\section{BMJ Paediatrics Open}

\title{
Parenting a newborn baby during the COVID-19 pandemic: a qualitative survey
}

Hailey Sledge (D) , ${ }^{1}$ Marguerite Lawler, ${ }^{1,2}$ Jonathan Hourihane, ${ }^{1,2}$ Ruth Franklin, ${ }^{2}$ Fiona Boland, ${ }^{3}$ Sumi Dunne, ${ }^{4}$ Naomi McCallion, ${ }^{1,5}$ Liam O’Mahony, ${ }^{6,7}$ Susan Byrne $e^{1,2,8}$

To cite: Sledge H, Lawler M, Hourihane J, et al. Parenting a newborn baby during the COVID-19 pandemic: a qualitative survey. BMJ Paediatrics Open 2022;6:e001348. doi:10.1136/ bmjpo-2021-001348

- Additional supplemental material is published online only. To view, please visit the journal online (http://dx.doi.org/ 10.1136/bmjpo-2021-001348).

Received 14 November 2021 Accepted 17 December 2021
Check for updates

\section{(C) Author(s) (or their} employer(s)) 2022. Re-use permitted under CC BY-NC. No commercial re-use. See rights and permissions. Published by BMJ.

For numbered affiliations see end of article.

Correspondence to Dr Susan Byrne; suabyrne@ rcsi.ie

\section{ABSTRACT}

Objective The COVID-19 pandemic caused long periods of lockdown, social isolation and intense challenges for parents. This study examines parenting in an infant cohort born at the pandemic onset.

Methods The CORAL study is a prospective longitudinal observational study looking at allergy, immune function and neurodevelopmental outcome in babies born between March and May 2020. Demographic information was collected, babies were reviewed at 6-monthly intervals, and serology for COVID-19 infection was recorded. When babies were 12 months old, parents were asked for 3-5 words to describe raising a baby during the pandemic. Frequency of word usage was compared between first time parents and parents with other children, and parents of babies with and without a diagnosis of COVID-19 infection.

Results 354 babies were recruited to CORAL study. Social circles were small. At 6 months the median number of people (including parents) who had kissed the baby was 3 , and by 12 months one-quarter of babies had never met another child of similar age. 304 parents completed the word choice. Commonly reported words were lonely (44.4\%), isolating (31.9\%) and strong bond (15.8\%). 12 of those 304 babies had COVID-19 in their first year of life and there was no significant difference in reported negative or positive word number compared with parents of babies without a COVID-19 infection, or by first time parents or those who already had children.

Conclusion The lockdowns and social restrictions made raising an infant challenging for all parents in Ireland. It is important parents know this was a shared experience.

\section{INTRODUCTION}

Public health responses to the SARS-CoV-2 (COVID-19) pandemic caused multiple lockdowns and long periods of social isolation. Reassuringly, we have recently demonstrated that lockdown was immunologically effective for babies, resulting in a low rate of COVID-19 among newborn infants. ${ }^{1}$ The Republic of Ireland went into lockdown in mid-March 2020. In the subsequent 13-month period, $87 \%$ of the time was spent in maximal (National Level 5) lockdown. ${ }^{1}$ For parents who had a baby during this period, the

\section{What is known about the subject?}

Public health responses to the SARS-CoV-2 (COVID-19) pandemic caused worldwide lockdowns and social isolation. How this impacted parenting in children born during the pandemic is unknown.

- There have been no reports of perceived parenting in a birth cohort of babies born during the pandemic.

\section{What this study adds?}

This study has explored the extent of infant social isolation and demonstrated that a quarter of infants had not met another infant in a social setting during the first year of their life.

- The lockdowns and social restrictions made raising an infant challenging for all parents with shared experiences of loneliness and isolation.

majority of their time had to be spent in a restricted social environment. We report here the specific experience of being the parent of an infant born, during the COVID-19 pandemic in Ireland.

Long periods of lockdown during the COVID-19 pandemic created new, intense challenges for parents and children alike: infants did not have had the opportunity to meet members of the extended family, such as grandparents, or have the opportunity to meet other babies. Children missed opportunities for face-to-face schooling and extracurricular social and sporting activities, while parents had to adapt to their own social isolation, including working from home and, in some cases, also becoming their child's teacher. ${ }^{2}$ The pandemic has generated greater parenting stress, higher anxiety, and an increase in reported depressive symptoms for some families. ${ }^{3}$ Couples with strong familial support and perceived control were found to experience milder stress, anxiety and fewer depressive symptoms, ${ }^{3}$ with 
isolation a common theme among new parents. ${ }^{4}$ Furthermore, families with children under 18 years have shown poorer mental health during the pandemic and both parents and children have reported overall reduced wellbeing. ${ }^{56}$ Parenting style in the first year of life has been found to be a significant predictor of future parental and child conduct, ${ }^{7-11}$ and therefore, it is important to understand the experience of parents who had children born during the pandemic. No study to date has looked at parenting in a cohort of infants recruited at the onset of the COVID-19 pandemic and followed prospectively, or at the impact of a COVID-19 diagnosis in babies on the overall parenting experience.

\section{METHODS}

The CORAL study-Impact of Corona Virus Pandemic on Allergic and Autoimmune Dysregulation in Infants Born During Lockdown-is a longitudinal prospective observational study of allergy, immune function and neurodevelopment in a population of Irish infants born from March to May 2020. ${ }^{1}$ Babies born during March to May 2020 were recruited. They had clinical review along with lateral flow COVID-19 antibody screening at 6 and 12 months of age. Detailed epidemiological information was collected at recruitment and at each 6-month review. As a marker of extended family contact, parents were asked at 6 months 'how many people have kissed your baby?' At 12 months, parents were asked for three to five words as free text describing their 'experience of raising a baby during the pandemic'. If parents wrote a sentence the most pertinent word was extracted. Every pertinent word was documented for each participant. The words were classified to be 'positive' or 'negative' in tone. Comparisons for the frequency of reported words were made between first time parents and parents with other children using chi-square test for independence. Statistical tests of comparison were conducted via STATA (SE V.16.1, StataCorp). Continuous data were described using mean (SD) and non-normal data using median (IQR). Adjustments were made for multiple comparisons. A word cloud was generated with WordItOut ${ }^{12}$ to display all the words parents had used to describe their experience. Only the size, not the colour, of the word relates to the frequency in which it was used by participants. To ensure anonymity, only words reported more than twice were included in the word cloud.

\section{Patient and public involvement}

This study was designed peripandemic and did not involve all stakeholders.

\section{RESULTS}

A total of 354 babies, born between March and May 2020, were recruited to the CORAL study. ${ }^{1}$ At birth, the median number of contacts outside the family home was 1 (IQR 1-4), increasing to 4 (IQR 2-7) by the 6-month visit. The median number of people who had kissed the baby in the first 6 months was 3 (IQR 2-4), this number included the parents of the child. By 12 months of age one in four babies $(25 \%)$ had never met another baby of the same age in a social setting.

The parents of 304 babies completed the free text word choice at 12 months $(86 \%) .44 .7 \%$ of the respondents were first time parents. Twelve of the 304 babies had COVID-19 in their first year of life (7 had PCR confirmed COVID-19, while an additional 5 babies had serological evidence of previous COVID-19 infection picked up on research screening).

A total of 304 parents reported 1320 words to describe their experience of raising a baby born during the pandemic (figure 1, online supplemental file 1). The most frequently reported words used by parents to describe their experience of parenting a new baby for the first 12 months during the COVID-19 pandemic and related lockdown were negative; lonely $(44.4 \%)$ and isolating $(31.9 \%)$. Other prominent negative words reported included: worrying $(15.5 \%)$, challenging $(14.5 \%)$ and exhausted/tiring (10.2\%). The most frequently reported positive words were at a lower frequency than the prominent negative words (above): strong bond/bonding time $(15.8 \%)$, time with family $(14.8 \%)$, calm/peaceful $(10.9 \%)$, rewarding $(7.9 \%)$ and happy $(7.6 \%)$. There was no significant difference in the frequency words reported by first time parents compared with parents of other children (table 1).

Parents reported an average of 2.4 negative and 1.7 positive words. First time parents reported 2.5 negative words and 1.7 positive words, and parents with other children reported 2.5 negative words and 1.6 positive words. There was no significant association between parenting first children and subsequent children, and the number of positive $(p=0.96)$ or negative words $(p=0.5)$.

On average, parents of babies who had acquired COVID-19 before 12 months did not report more negative (2.6) or positive words (1.7) than parents of babies without COVID-19 infection.

\section{DISCUSSION}

The COVID-19 pandemic has taken a global toll, affecting people in different ways. It is likely that repeated mass lockdowns and social distancing restrictions made raising an infant different and more difficult than usual for all parents. Our longitudinal, prospective observational CORAL study has given direct insight into parental experiences of raising an infant born during the pandemic, with almost half of parents spontaneously choosing the word lonely, and a third the word isolating to describe their experience. Indeed, we have demonstrated that families' social circles between birth and 6 months were very small.

Positive words were less commonly used. However, $a$ strong bond and time with family were two of the top five most frequently reported positive words. While the experience was reported to be a tremendous challenge, the 


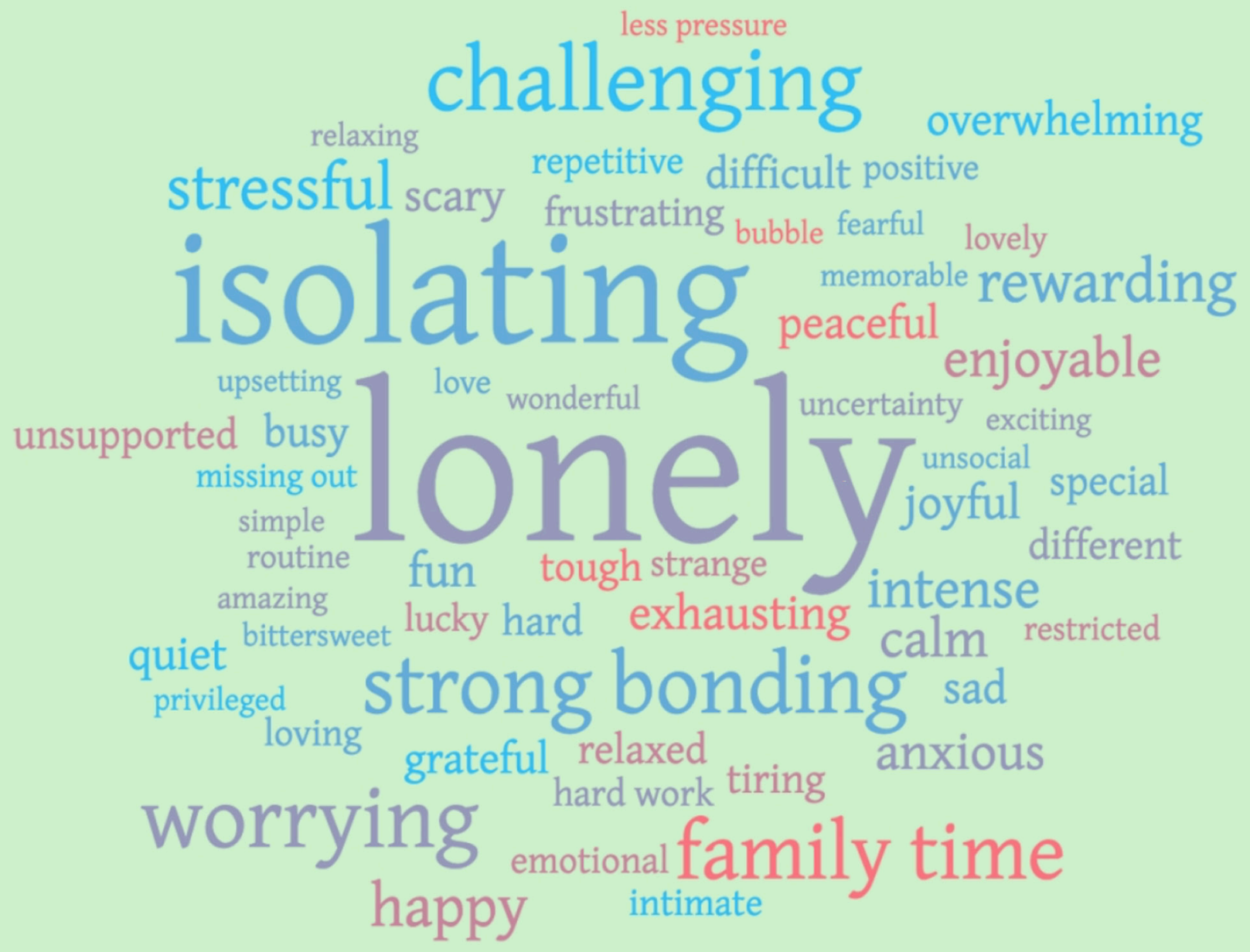

Figure 1 Words used by parents to describe the experience of raising a baby born during the pandemic. The size of the word represents the frequency at which it was reported. This figure was created by the authors with permission to publish, created using WordltOut.

opportunity for increased bonding time was reported to be enjoyable and rewarding. We previously demonstrated that the breastfeeding rates at 6 months were higher than national norms for this cohort of children. ${ }^{1}$ There was no difference in the frequency of reported words between parents having their first and subsequent child. In addition, there was no apparent difference in number of positive and negative words used between parental reports of children who did and did not get COVID-19.

An infant's first year of life comes with many changes and adjustments for parents. Parental stress can occur when there is a discrepancy in the demands of parenthood and the support parents think is available to them, such as family resources and psychological assistance. ${ }^{13} 14$ A number of parents in this study commented on their experience of the lack of support from health and social services during this time and many parents commented on the sadness and disappointment that they felt by not having input from extended members of the family including grandparents, and close friends. This is graphically reflected in the small number of people who kissed the children in their first 6 months of life. If we assume that most children were kissed by two parents, then only one other person kissed the baby in the first 6 months of life. Our study demonstrates that small social circles have led to feelings of isolation and loneliness among parents during the pandemic. In addition to small social circles, one in four of the infants in our cohort had never met another similarly aged child by the age of 12 months. Only time will tell how limited social interaction and lack of peer contact will affect the development of social communication skills in these babies.

Potential further studies could expand on differences between the CORAL cohort and a historic control birthcohort, as well as follow-up on the long-term impacts of pandemic-associated isolation. Additionally, studies exploring what support and services could have been strengthened to prevent feelings of loneliness and isolation would be useful to allow policy-makers to make provisions for those at higher risk of social isolation after having a baby.

We acknowledge that this study has limitations. Due to the global pandemic, it was not possible to have a control cohort. We do not have normative data about the size of 
Table 1 Most commonly used words to describe parenting in the pandemic

\begin{tabular}{llllll}
\hline Negative words & \multicolumn{5}{l}{ Positive words } \\
\hline Lonely $(\mathrm{p}=0.91)$ & $135 / 304$ & $44.40 \%$ & Strong bonding $(\mathrm{p}=1.0)$ & $48 / 304$ & $15.80 \%$ \\
1st time parent & $59 / 136$ & $43.40 \%$ & 1st time parent & $21 / 136$ & $15.40 \%$ \\
1+ other children & $75 / 168$ & $44.60 \%$ & 1+ other children & $27 / 168$ & $16.10 \%$ \\
Isolating $(\mathrm{p}=0.71)$ & $97 / 304$ & $31.90 \%$ & Family time $(\mathrm{p}=0.87)$ & $45 / 304$ & $14.80 \%$ \\
1st time parent & $45 / 136$ & $33.10 \%$ & 1st time parent & $21 / 136$ & $15.40 \%$ \\
1+ other children & $52 / 168$ & $31.00 \%$ & 1+ other children & $24 / 168$ & $14.30 \%$ \\
Worrying $(\mathrm{p}=0.87)$ & $47 / 304$ & $15.50 \%$ & Calm/peaceful $(\mathrm{p}=0.58)$ & $34 / 304$ & $10.90 \%$ \\
1st time parent & $20 / 136$ & $14.70 \%$ & 1st time parent & $17 / 136$ & $12.50 \%$ \\
1+ other children & $27 / 168$ & $16.10 \%$ & 1+ other children & $17 / 168$ & $10.10 \%$ \\
Challenging $(p=0.10)$ & $44 / 304$ & $14.50 \%$ & Rewarding $(\mathrm{p}=0.03)$ & $24 / 304$ & $7.90 \%$ \\
1st time parent & $25 / 136$ & $18.40 \%$ & 1st time parent & $16 / 136$ & $11.80 \%$ \\
1+ other children & $19 / 168$ & $11.30 \%$ & 1+ other children & $8 / 168$ & $4.80 \%$ \\
Exhausted/tiring $(\mathrm{p}=0.71)$ & $31 / 304$ & $10.20 \%$ & Happy $(\mathrm{p}=0.83)$ & $23 / 304$ & $7.60 \%$ \\
1st time parent & $15 / 136$ & $11.00 \%$ & 1st time parent & $11 / 136$ & $8.10 \%$ \\
1+ other children & $16 / 168$ & $9.50 \%$ & 1+ other children & $12 / 168$ & $7.10 \%$ \\
\hline
\end{tabular}

Comparisons were made for response between first-time parents and parents who welcomed another child. Adjustment made for multiple comparisons set significance at 0.005 .

Irish babies' social circles or 'kiss contacts' before the pandemic. Parents were only asked for single words to describe parenting on one occasion at 12 months. Questionnaires were sent to the family home, but no data was collected on whether the form reflected the view of one parent or both parents. No formal indices of parental depression or anxiety were used. However, it was not our aim to look at parental mood but rather to understand the collective parental experience. Ireland had a very strict public health-driven social isolation policy compared with other countries and we acknowledge that the Irish parenting experience may differ from other regions with different social isolation policies.

\section{CONCLUSION}

Throughout the pandemic, there were many media reports that restrictions of social interactions left parents feeling alone and unsupported. Whether they became new parents during the pandemic or added another child to their family, Irish parents in the CORAL study had small social circles and overwhelmingly reported loneliness and isolation, while acknowledging that it did provide a time to develop a strong bond and spend time with their new baby. It is important for parents to know that the experiences of parenting during the lockdown were a shared experience. Policy-makers should acknowledge the impact of social isolation on families and make provisions for support and resources, especially for those at risk of isolation.

\section{Author affiliations}

${ }^{1}$ Department of Paediatrics, Royal College of Surgeons in Ireland, Dublin, Ireland

${ }^{2}$ Department of Paediatrics, Children's Health Ireland, Dublin, Ireland
${ }^{3}$ Data Science Centre, Royal College of Surgeons in Ireland, Dublin, Ireland ${ }^{4}$ Department of General Practice, Royal College of Surgeons in Ireland, Dublin, Ireland

${ }^{5}$ Maternity Hospital, Rotunda Hospital, Dublin, Ireland

${ }^{6}$ Department of Medicine and School of Microbiology, University College Cork, Cork, Ireland

${ }^{7}$ APC Microbiome Ireland, University College Cork, Cork, Ireland

${ }^{8}$ FutureNeuro, Royal College of Surgeons in Ireland, Dublin, Ireland

Contributors $\mathrm{HS}$ analysed data and wrote the paper. ML collected data and edited the paper. $\mathrm{JH}$ is PI of the CORAL study. He conceived of and designed the CORAL study, recruited participants, collected data, analysed the data and wrote the paper. RF recruited participants, collected data and edited the paper. FB provided statistical input and edited the paper. SD assisted in data interpretation and edited the paper. NM codesigned the study, recruited participants, and edited the paper. LO'M codesigned the study and edited the paper. SB codesigned the study, collected data, analysed data, wrote the paper, and is the study guarantor.

Funding This work was supported by Temple Street Hospital Foundation in Dublin, Ireland (no grant/award number) and the Clemens Von Pirquet Foundation in Geneva, Switzerland (no grant/award number).

Competing interests LO'M received research funding from GSK and Chiesi Pharmaceuticals; speaker support from Nestle, Nutricia, Reckitt and Abbott; consultant with PrecisionBiotics. JH is a board member of Clemens Von Pirquet Foundation. No other conflicts declared.

Patient consent for publication Not applicable.

Ethics approval Ethical permission was granted by the National Covid Ethics Committee (20-NREC-COV-067).

Provenance and peer review Not commissioned; externally peer reviewed.

Data availability statement All data relevant to the study are included in the article or uploaded as online supplemental information. Not applicable.

Supplemental material This content has been supplied by the author(s). It has not been vetted by BMJ Publishing Group Limited (BMJ) and may not have been peer-reviewed. Any opinions or recommendations discussed are solely those of the author(s) and are not endorsed by BMJ. BMJ disclaims all liability and responsibility arising from any reliance placed on the content. Where the content includes any translated material, BMJ does not warrant the accuracy and reliability of the translations (including but not limited to local regulations, clinical guidelines, terminology, drug names and drug dosages), and is not responsible 
for any error and/or omissions arising from translation and adaptation or otherwise.

Open access This is an open access article distributed in accordance with the Creative Commons Attribution Non Commercial (CC BY-NC 4.0) license, which permits others to distribute, remix, adapt, build upon this work non-commercially, and license their derivative works on different terms, provided the original work is properly cited, appropriate credit is given, any changes made indicated, and the use is non-commercial. See: http://creativecommons.org/licenses/by-nc/4.0/.

ORCID iD

Hailey Sledge http://orcid.org/0000-0001-5812-9382

\section{REFERENCES}

1 Lawler M, Franklin R, McCallion N, et al. The impact of COVID-19 lockdown on infants' coronavirus exposure and routine healthcare access in Ireland: The CORAL birth cohort study at 6 months. Pediatr Allergy Immunol 2021;32:1876-9.

2 Cluver L, Lachman JM, Sherr L, et al. Parenting in a time of COVID-19. Lancet 2020;395:e64.

3 Brown SM, Doom JR, Lechuga-Peña S, et al. Stress and parenting during the global COVID-19 pandemic. Child Abuse Negl 2020;110:104699.

4 DeYoung SE, Mangum M. Pregnancy, birthing, and postpartum experiences during COVID-19 in the United States. Front Sociol 2021;6:611212.

5 Gadermann AC, Thomson KC, Richardson CG, et al. Examining the impacts of the COVID-19 pandemic on family mental health in
Canada: findings from a national cross-sectional study. BMJ Open 2021:11:e042871.

6 Chu KA, Schwartz C, Towner E, et al. Parenting under pressure: a mixed-methods investigation of the impact of COVID-19 on family life. J Affect Disord Rep 2021;5:100161.

7 Moe $\mathrm{V}$, von Soest T, Fredriksen $\mathrm{E}$, et al. The multiple determinants of maternal parenting stress 12 months after birth: the contribution of antenatal attachment style, adverse childhood experiences, and infant temperament. Front Psychol 2018;9:1987.

8 Crnic KA, Gaze C, Hoffman C. Cumulative parenting stress across the preschool period: relations to maternal parenting and child behaviour at age 5. Infant Child Dev 2005;14:117-32.

9 Jones JD, Cassidy J, Shaver PR. Parents' self-reported attachment styles: a review of links with parenting behaviors, emotions, and cognitions. Pers Soc Psychol Rev 2015;19:44-76.

10 Wagner NJ, Propper C, Gueron-Sela N, et al. Dimensions of maternal parenting and infants' autonomic functioning Interactively predict early internalizing behavior problems. J Abnorm Child Psychol 2016;44:459-70.

11 Lahey BB, Van Hulle CA, Keenan K, et al. Temperament and parenting during the first year of life predict future child conduct problems. J Abnorm Child Psychol 2008;36:1139-58.

12 Enideo. Transform your text into word clouds! [Internet]. WordltOut, 2021. Available: https://worditout.com/

13 Abidin RR. Parenting stress index. 3rd ed. Lutz, FL: Psychological Assessment Resources, 1995.

14 Deater-Deckard K, Dodge KA, Bates JE, et al. Multiple risk factors in the development of externalizing behavior problems: group and individual differences. Dev Psychopathol 1998;10:469-93. 